\title{
Unified methodology for characterisation of global fatigue damage evolution in adhesively bonded joints
}

\author{
Pankaj R. Jaiswal, Rahul Iyer Kumar, Wim De Waele \\ Soete Laboratory, Department of Electromechanical, Systems and Metal Engineering (EMSME), Ghent University, Belgium. \\ Pankaj.Jaiswal@Ugent.be, bttps:/ / orcid.org/0000-0002-9373-4489 \\ Rabul.IyerKumar@Ugent.be,http://orcid.org/0000-0003-1241-2697 \\ Wim.DeWaele@Ugent.be,http://orcid.org/0000-0002-7196-3328
}

\begin{abstract}
This paper reports on the development of a methodology for evaluating the fatigue damage evolution in single and double lap adhesively bonded joints subjected to constant and variable fatigue loading. First, a methodology is developed to monitor the evolution of permanent deformation, stiffness degradation and hysteresis losses of single lap joints subjected to constant amplitude fatigue load. During the test, the global deformation of the adhesive joint is monitored using digital image correlation (DIC). A MATLAB code is developed to analyse and visualize the evolution in stiffness degradation and energy dissipation during the course of a complete fatigue test. Hereto ellipses are fitted to the hysteresis loops in the recorded load-deformation data. The slope of the main axis of the ellipse and its enclosed area are extracted to determine stiffness and dissipated energy, respectively. Next, the methodology is optimized for implementation during fatigue testing of double lap joints with different bond line thicknesses. The results of the experimental study reveal a distinct relation between stiffness degradation and increase in hysteresis losses with increasing number of fatigue cycles or thus increasing fatigue damage.
\end{abstract}

KEYwORDS. Single lap adhesive joint; Double lap adhesive joint; Fatigue test; Hysteresis.

\section{OPEN ACCESS}

Citation: Jaiswal, P. R., Kumar, R. I., De Waele, W., Unified methodology for characterisation of global fatigue damage evolution in adhesively bonded joints, Frattura ed Integrità Strutturale, 53 (2020) 26-37.

Received: 30.11 .2019

Accepted: 28.04 .2020

Published: 01.07.2020

Copyright: (C) 2020 This is an open access article under the terms of the CC-BY 4.0, which permits unrestricted use, distribution, and reproduction in any medium, provided the original author and source are credited.

\section{INTRODUCTION}

A dhesives are widely applied for joining dissimilar materials, and adhesive joints are most noticeable for the development of lightweight structures in aviation, ships or trains as it directly affects fuel economy [1]. In fact, it has been reported that $7 \%$ enhancement in fuel efficiency could result from a weight reduction of $10 \%$ for a vehicle structure [2]. Whilst in automotive industry spot-welded joints are widely used to reach this purpose [3], the shipbuilding industry has shown a high interest in adhesive bonding. Fiber-reinforced polymers are increasingly being used in the 
superstructure of ships [4,5], and adhesive bonding is considered to be a robust and reliable joining technology for the connection of primary and secondary ship structures. However, the durability of the adhesive joint is one of the main challenges and currently limits the utilisation of adhesive bonding [6, 7]. Therefore, it is necessary to evaluate the fatigue performance of an adhesively bonded joint so as to provide a guarantee of its safety for an extended period of service life. Several researchers have performed experimental studies to evaluate the fatigue life of adhesives and adhesive joints. Colombi and Fava [8] evaluated the fatigue performance and stiffness degradation of double lap adhesive joints, steel bonded to CFRP with a $1.1 \mathrm{~mm}$ thick epoxy adhesive layer, subjected to fatigue tests at stress ratios equal to 0.1 and 0.4 at a frequency of $12 \mathrm{~Hz}$. They observed that with an increasing number of fatigue cycles the debonding and hysteretic energy loss increase and the joint stiffness decreases. The effect of stress ratio on fatigue life of the adhesive joint was considered negligible. Likewise, the durability and crack propagation of single lap aluminum-GFRP specimens bonded with $0.1 \mathrm{~mm}$ twocomponent structural epoxy paste (Araldite 2015) were investigated for various load ratios in four-point bending tests by Zamani et al. [9]. It was shown that crack initiation life was equal to almost half of the total life for a maximum fatigue load equal to $50 \%$ of the static failure load whereas it is negligible for maximum fatigue loads higher than $60 \%$ of the static failure load. Afendi et al. [10] studied the strength of single-lap hybrid joints (a combination of bolts and $0.2 \mathrm{~mm}$ thick adhesive layer) with similar and dissimilar adherends (aluminium alloy AA7075 and glass fibre reinforced epoxy). Three different joint configurations were aged for 20 to 120 days at a temperature of 50 degrees under a moist environment and fatigue loaded for 781000 cycles. The dissimilar specimen configuration showed the highest joint strength and the largest failure strain compared to specimens based on similar adherends. Similarly, Machado et al. [11] studied the performance of single lap joints with similar (CFRP- CFRP) and disimilar (CFRP- Aluminium 5754H22) substrates bonded by a $0.2 \mathrm{~mm}$ layer of XNR6852 E-3 epoxy. Specimens were fatigue cycled in the following conditions: unaged, aged and dried after hydrothermal ageing. The experimental results allowed to conclude that the fatigue performance of joints can be affected by changes induced by the drying process or losses in the interface strength and that the dissimilar combination of substrates sustains higher number of cycles to failure. Ayatollahi et al. [12] and Razavi et al.[13] evaluated the fatigue performance of adhesively bonded single lap joints with non-flat sinusoid and zigzag interfaces, respectively. Two aluminium (7075-T6) adherends were bonded with a $0.2 \mathrm{~mm}$ thick two-component epoxy-based adhesive (UHU Plus Endfest 300). Both types of joints have been subjected to constant amplitude fatigue with a load ratio of 0.1 at a frequency of $7 \mathrm{~Hz}$. The results demonstrated that the fatigue strength and life of the joints with the non-flat interfaces is significantly higher than for reference joints with a flat interface. Kałuża et al. [14] studied the bond behaviour of double lap (steel-to-CFRP) adhesive joints subjected to fatigue loading at a frequency of $5 \mathrm{~Hz}$. They determined the most suitable type of methacrylate adhesive based on the test results for seven different methacrylate adhesives. All previously discussed references focus on thin adhesives. To the best of our knowledge, there is no scientific literature on fatigue damage evolution of thick methyl metacrylate adhesive bonds for joining steel and CFRP.

The main objective of this work is to develop and evaluate a methodology to quantify the evolution of fatigue damage during constant amplitude tensile fatigue (CATF) tests and variable amplitude tensile fatigue (VATF) tests. First, a methodology is developed to monitor the evolution of damage in single lap adhesive joint (SLAJ) specimens subjected to a CATF test. Digital Image Correlation (DIC) is used to measure the global elongation of the adhesive joint [15,16]. A MATLAB routine is developed to post-process the fatigue test data and to quantify and visualize the evolution of global damage in terms of permanent deformation, stiffness degradation and hysteresis losses. Second, the methodology has been optimized towards CATF and VATF testing of double lap adhesive joint (DLAJ) specimens with two different bond line thicknesses.

\section{MATERIALS AND SPECIMENS}

or the experimental work, a two-component methyl methacrylate (MMA) adhesive was used. The selected adhesive exhibits promising properties of high strength and high ductility [14]. The main mechanical properties of the MMA adhesive are summarized in Tab. 1.

\section{Substrates and surface treatment}

Conventional S235 carbon steel and high strength shipbuilding steel AH36 (having a minimum specified yield stress of $350 \mathrm{MPa})$ were selected for the substrates of a single-lap adhesive joint and a double lap adhesive joint configuration respectively. Carbon fibre reinforced polymer (CFRP) laminates with a minimum tensile strength of $658 \mathrm{MPa}$ were selected as strap material for the DLAJ specimens. 
For manufacturing of the SLAJ specimens, the substrates were saw-cut from a steel plate to nominal dimensions of $104 \mathrm{x}$ 25 x $6 \mathrm{~mm}$ (length $\mathrm{x}$ width $\mathrm{x}$ thickness). This was followed by sandblasting of the surface (interface between substrate and adhesive) up to a roughness of approximately $2.5 \mu \mathrm{m}$, and cleaning with acetone prior to bonding. Sandblasting increases the roughness of the surface, which will enhance the adhesive strength of the joint. Care was taken as excessive roughness is known to decrease the strength of the joint [17].

\begin{tabular}{cc}
\hline Property & MMA \\
Tensile strength $[\mathrm{MPa}]$ & $12-15$ \\
Maximum Tensile Elongation $[\%]$ & $40-60$ \\
Tensile modulus $[\mathrm{MPa}]$ & $207-276$ \\
Lap Shear strength $[\mathrm{MPa}]$ & $16-19$ \\
Service temperature range $\left[{ }^{\circ} \mathrm{C}\right]$ & -40 to +82 \\
\hline
\end{tabular}

Table 1: Main mechanical properties of MMA [14,18].
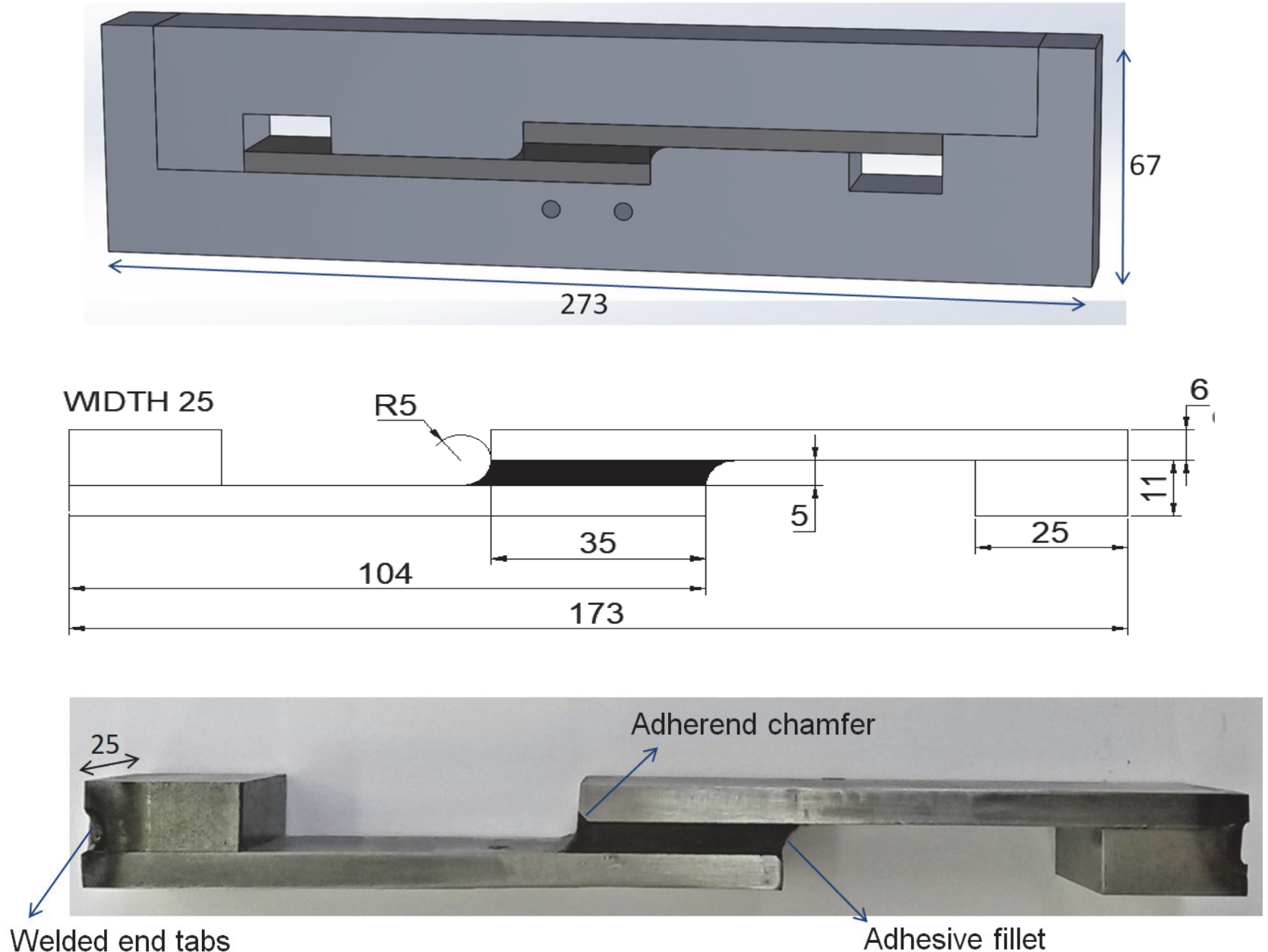

Figure 1: (a) A three-dimensional representation of the fixture used for the production of SLAJ specimens, (b) Schematic diagram of a single-lap adhesive joint, (c) Produced SLAJ specimen. (All dimensions are in $\mathrm{mm}$ ) 
Production of single and double adhesive lap joint specimens

In this work, two different types of adhesively bonded specimens were manufactured. In a first series, a total of eight SLAJ specimens with $6 \mathrm{~mm}$ thick steel substrates were produced. The bond line thickness was controlled to $5 \mathrm{~mm}$ by using the mould presented in Fig. 1(a). The curing of the adhesive was done at room temperature for 24 hours according to the supplier guidelines. Essential aspects of the joint are the adherend chamfers and adhesive fillets for reducing stress concentrations at the ends of the bonded area. The reduced stress concentrations should improve fatigue strength and extend the lifetime. The geometry and dimensions have been roughly based on standard ASTM D1002 [19] and are illustrated in Fig. 1(b). After manufacturing, the edges of the substrates along the overlap were prepared with the use of a hand grinder, in order to obtain an acceptable surface finish for DIC speckling (see further). Additionally, alignment tabs were welded to each adherend, to reduce the geometrical eccentricity of the joint while loading. The final appearance of an SLAJ specimen is shown in Fig. 1(c).

In a second series, a total of six DLAJ specimens with $8 \mathrm{~mm}$ thick steel (AH36) and $3 \mathrm{~mm}$ thick composite (CFRP) substrates were produced with two different bond line thicknesses $(4 \mathrm{~mm}$ and $8 \mathrm{~mm}$ ) in the actual working environment of the maritime industry (Damen Schelde Naval Shipbuilding, the Netherlands). Steel substrate surface preparation was performed identically as described for the SLAJ specimens. The schematic diagram of the DLAJ specimen is illustrated in Fig. 2.

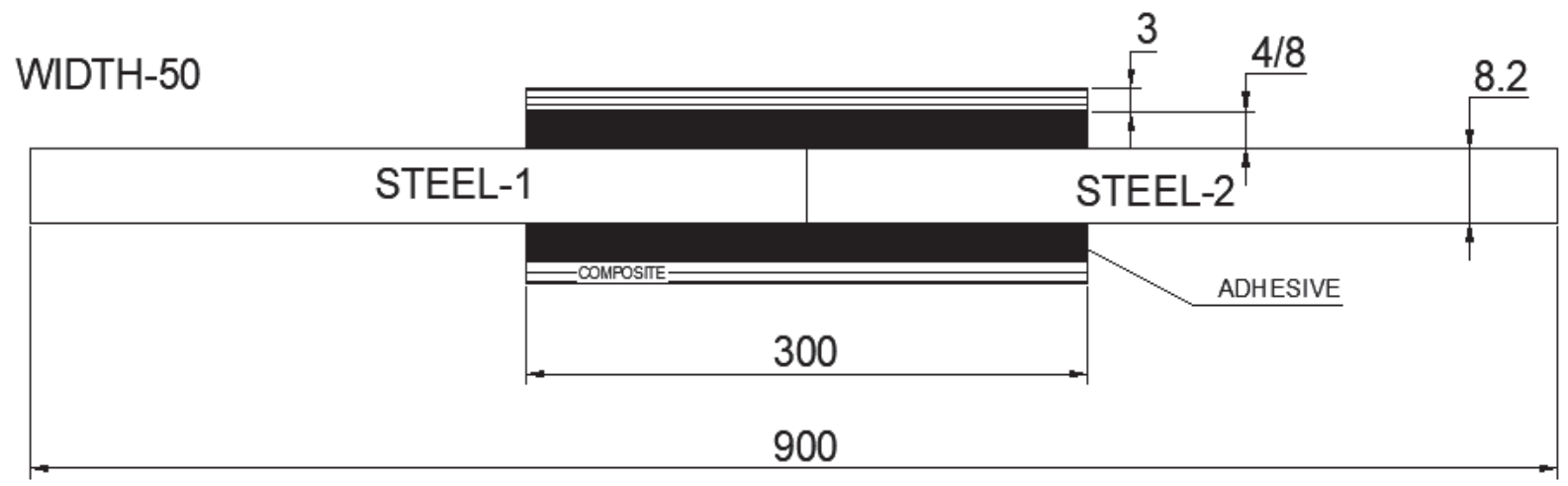

Figure 2: Schematic diagram of double lap adhesive joint specimen.

\section{FATIGUE TESTING METHODOLOGY}

he fatigue tests on SLAJ specimens were performed at room temperature on an ESH servo-hydraulic machine with a maximum load capacity of $100 \mathrm{kN}$. The fatigue tests on DLAJ specimens have been performed on an ESH machine with $150 \mathrm{kN}$ load capacity. To allow a detailed study of fatigue damage evolution, the load and the global elongation of the adhesive joint need to be recorded throughout the test. For the DLAJ specimens, the elongation of the joint can be accurately approximated by the load-line displacement recorded by the machine. The asymmetry and flexibility of the SLAJ specimens do not allow to use the load-line displacement. Therefore digital image correlation (DIC) was used to determine the elongation of the joint during fatigue testing.

DIC is a contactless deformation measurement method, which uses digitally captured images of a surface of the test specimen. A detailed description of the DIC technique can be found in [20,21]. It requires a high contrast surface to maintain a good correlation between the captured images during post-processing. Hereto a black speckle pattern (randomly distributed paint dots) is applied over the bright white background of the specimen's surface of interest. The general requirement for the speckled surface is around $50 \%$ black and $50 \%$ white. A speckle size of $0.042 \mathrm{~mm}$ was aimed at, which results in a measurement accuracy of $100 \mu \varepsilon$ [22,23]. A schematic representation of the test setup, including speckled specimen, light sources and cameras is shown in Fig. 3(a). On the one hand, DIC has been used to evaluate the strains inside the adhesive joint (not reported in this paper). On the other hand, it was used to record the relative vertical displacement between two markers P0 and P1 (see Fig. 3(b)), one on each steel adherend, which serves as an accurate approximation of the global elongation of the adhesive joint.

The goal of the above is to accurately determine the relation between applied tensile force and the corresponding elongation of the adhesive joint during a single load cycle. Due to the viscoelastic behaviour of the adhesive, hysteresis will occur during each load cycle. It means that the load versus elongation curve during loading and unloading follows different trajectories, 
thus forming a hysteresis ellipse for each fatigue cycle. Based on the characteristics of this ellipse, three essential parameters can be determined, as indicated in Fig. 4.

- The displacement of the centre of the ellipse $X_{0}$.

- The slope of the centre line, quantified by angle $\emptyset$, representing the stiffness of the joint.

- The enclosed surface area ' $\mathrm{A}$ ' as an indication of the dissipated energy.

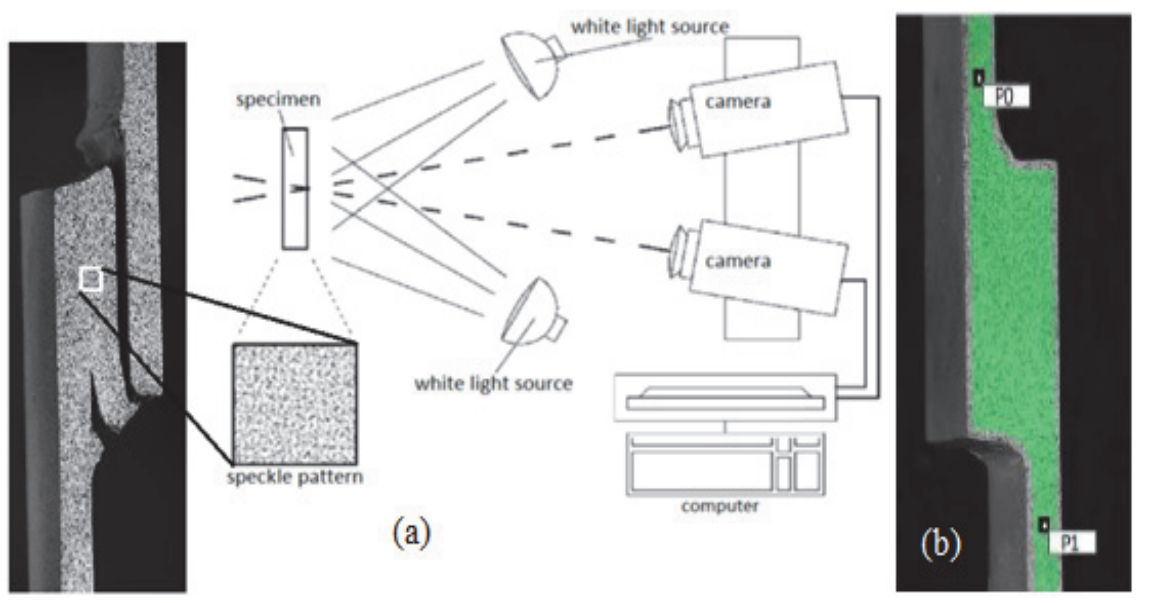

Figure 3: (a) Schematic layout of DIC set up [15], (b) Characterisation of the global deformation of the adhesive joint by tracking the relative vertical displacement of two virtual markers $\left(\mathrm{P}_{0}-\mathrm{P}_{1}\right)$.

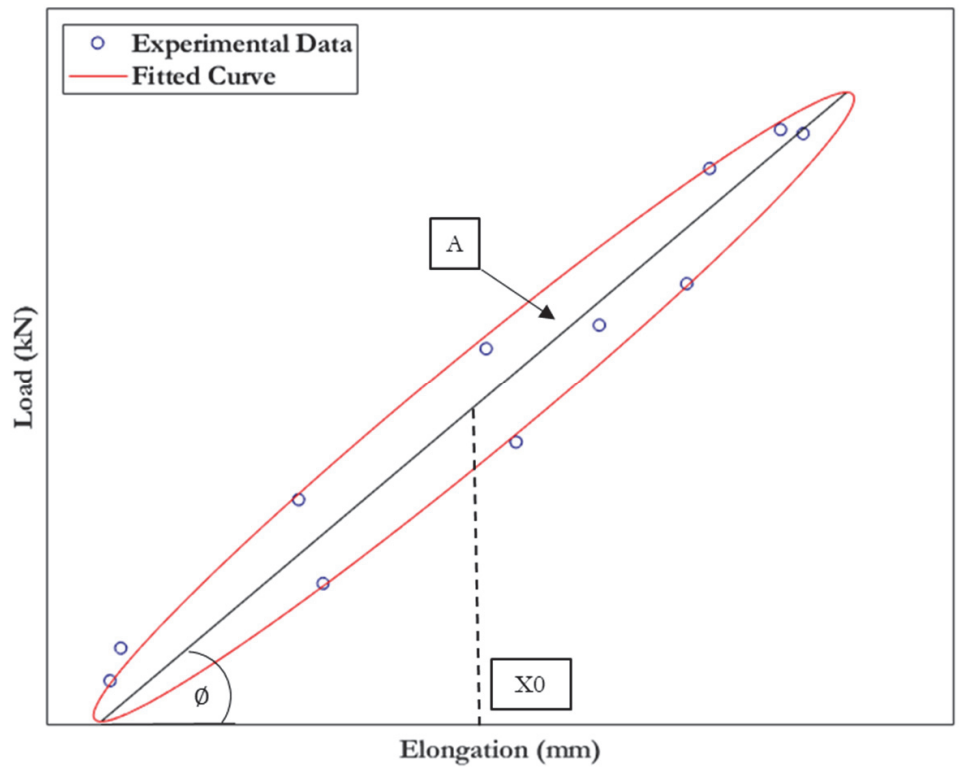

Figure 4: A typical load-elongation hysteresis ellipse recorded during a fatigue test on SLAJ specimen.

A similar approach for the identification of hysteresis loops obtained during fatigue testing of a structural epoxy adhesive has been reported in [24]. A post-processing routine to calculate and plot the evolution in stiffness degradation, hysteretic energy dissipation and permanent elongation during a complete fatigue cycle was developed in MATLAB code. The displacement of the centre gives an indication of the amount of permanent, viscoplastic deformation that has occurred. The slope of the main axis of the ellipse relates to the stiffness of the joint; a decrease in slope during the test indicates an accumulation of damage [25,26]. An increase in the enclosed area is a measure for the increased dissipation of mechanical energy [27]. In order to avoid the impact of viscous behaviour or excessive heat dissipation on the durability of the adhesive joint, the fatigue tests were performed at frequencies of 2 and $4 \mathrm{~Hz}$. Marcadon et al. [28] performed fatigue tests on T-joints for marine applications at $0.2,1$ and $5 \mathrm{~Hz}$ and concluded that the fatigue damage at the lowest frequency was most probably influenced by viscous behaviour. The selected test frequencies also comply with the DNVGL-RP-C301 standard [29], which 
recommends a maximum loading frequency of $4 \mathrm{~Hz}$. Temperature measurements performed with a handheld thermometer (FLUKE-68) during fatigue testing and focusing on the adhesive proved that no noticeable heat dissipation occurred. This is important since self-heating of the adhesive would affect its mechanical properties and damage evolution.

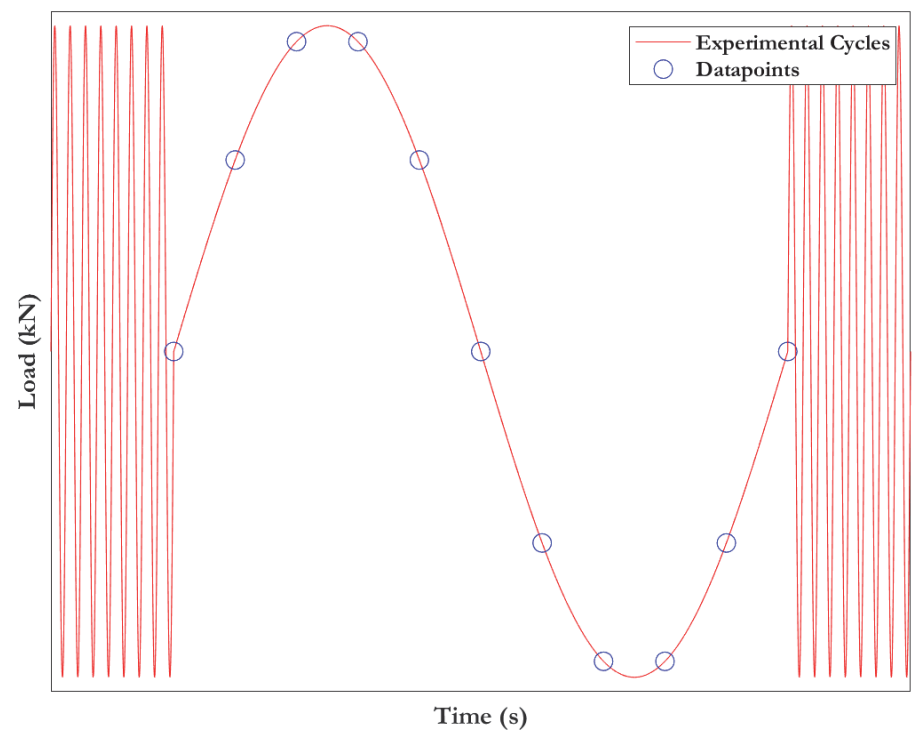

Figure 5: Data are acquired at discrete time steps during a slow load cycle $(0.1 \mathrm{~Hz})$ following an interval of 99 fast cycles $(2 \mathrm{~Hz})$.

The development of the methodology is based on the group of SLAJ specimens, tested at a frequency of $2 \mathrm{~Hz}$. In order to ensure manageable DIC data file sizes and reducing the post-processing time, data acquisition has been performed at distinct time intervals. After every series of 99 fatigue cycles (at $2 \mathrm{~Hz})$, a single slow cycle $(0.1 \mathrm{~Hz})$ was included because the rate of image capturing by the DIC cameras is limited to 1 picture per second. This allows to determine 10 DIC-based elongation measurements during one slow cycle; a similar methodology is reported in [30]. Load versus elongation data were collected during the slow cycle in order to construct one hysteresis ellipse; a typical plot with experimental data and the fitted loadelongation loop is shown in Fig. 4. It can be observed that the implemented data acquisition and data post-processing allow characterizing a fatigue hysteresis cycle with reasonable accuracy; only a few outliers do not perfectly fit the hysteresis ellipse. The synchronisation of the test rig control system and the DIC data acquisition system is illustrated in Fig. 5.

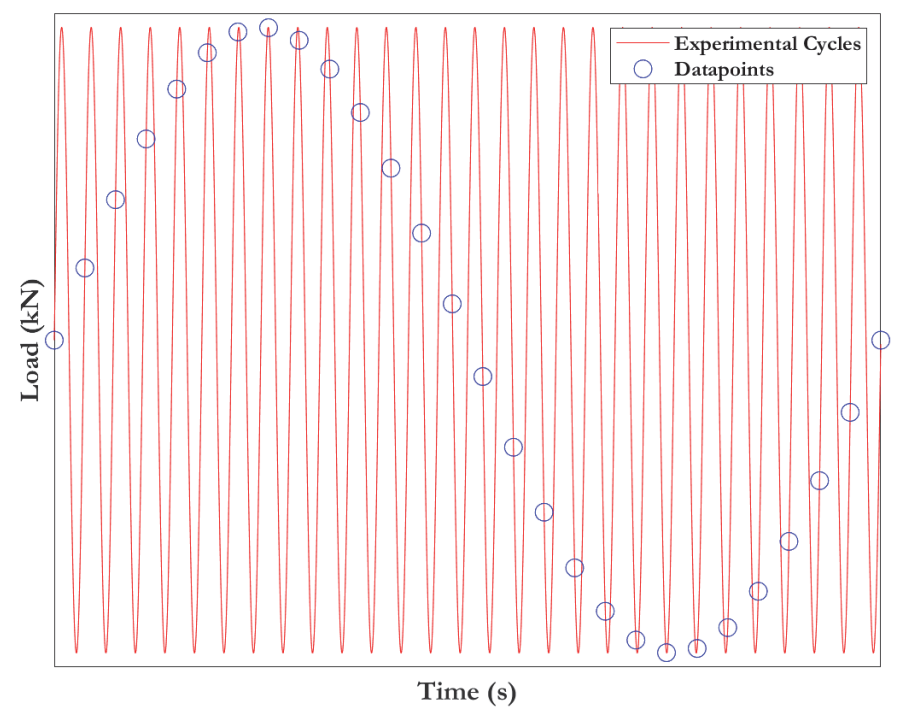

Figure 6: A sinewave for storing data after an interval of 2000 working cycles. 
In order to improve the methodology of global fatigue damage evolution, a fatigue test was performed at a frequency of 4 $\mathrm{Hz}$, and DIC images were captured at a rate of $3.846 \mathrm{~Hz}$. A total of 25 images were post-processed to construct one hysteresis ellipse, as shown in Fig. 6. The synchronisation of the data acquisition and DIC cameras was implemented in such a way that the DIC cameras are triggered frequently, at an interval of every 2000 fatigue cycles. The same methodology was also reported in $[25,26]$. A representative load-displacement output resulting from this methodology is shown in Fig. 7 . Outliers are eliminated and the fitted ellipse fit excellently represents the collection of experimental data points.

\section{RESULTS AND DISCUSSION}

he fatigue results of SLAJ and DLAJ specimens are discussed in the following two subsections. The first subsection discusses the fatigue testing methodology applied to SLAJ specimens subjected to constant amplitude fatigue loading. The second subsection reports the results of the DLAJ specimens subjected to constant and variable amplitude fatigue loading.

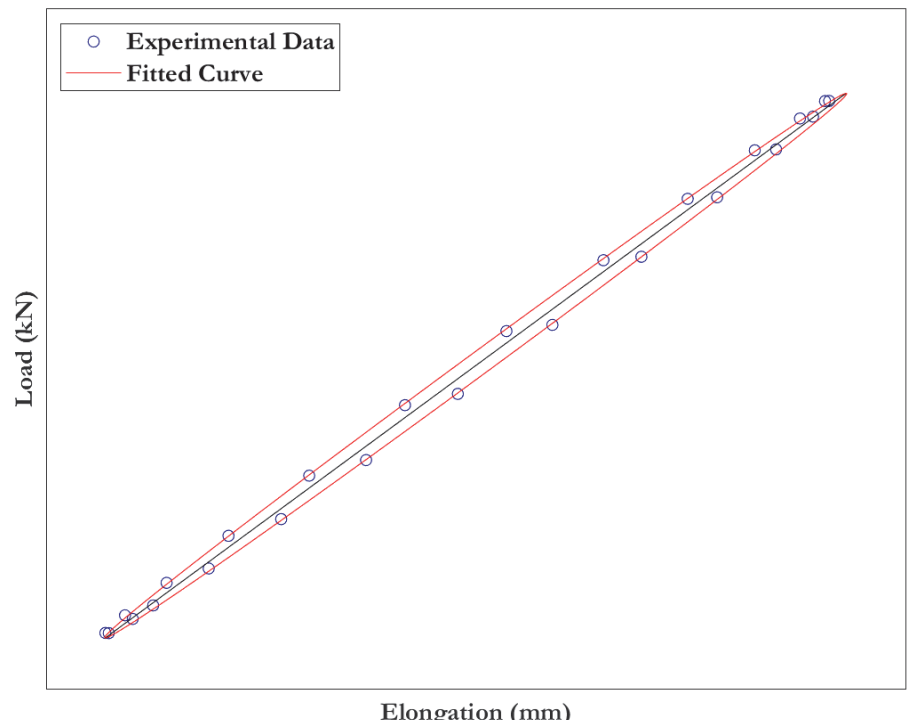

Figure 7: A load-elongation hysteresis ellipse (SLAJ).

\begin{tabular}{cccccc}
\hline Sample ID & $\begin{array}{c}\text { Range of load } \\
\text { amplitude (min- } \\
\text { max) kN }\end{array}$ & $\begin{array}{c}\text { Fatigue } \\
\text { life } \\
\text { (cycles) }\end{array}$ & Frequency (Hz) & $\begin{array}{c}\text { Status of a } \\
\text { sample at the } \\
\text { end of the test }\end{array}$ & $\begin{array}{c}\text { Load Ratio } \\
(\mathrm{R}=\text { Fmin } / \text { Fmax })\end{array}$ \\
SG-05 & $0.6-6$ & 3119 & 2 & Fail & 0.1 \\
SG-04 & $0.5-5$ & 15900 & 4 & Fail & 0.1 \\
SG-06 & $0.4-4$ & 100000 & 2 & Intact & 0.1 \\
SL-06 & $0.7-7$ & 100000 & 4 & Fail & 0.1 \\
\hline
\end{tabular}

Table 2: Overview of fatigue tests performed on SLAJ specimens.

\section{Single lap adhesive joint}

To define a suitable range of fatigue load amplitudes, four SLAJ specimens have first been subjected to quasi-static tensile tests at a displacement rate of $1 \mathrm{~mm} / \mathrm{min}$. The maximum failure load observed was $8 \mathrm{kN}$, and all specimens exhibited a relatively high elongation at failure. Next, four tensile fatigue tests were conducted on SLAJ specimens at a load ratio $R=0.1$ and different maximum load levels (i.e. $87.5 \%, 75 \%, 62.5 \%$ and $50 \%$ of the maximum observed ultimate tensile strength $8 \mathrm{kN})$. The fatigue test details are summarized in Tab. 2. Specimens SG-05, SG-04 and SL ${ }^{1}-06$ have been tested up to failure, while the fatigue test on specimen SG-06 was stopped at $10^{5}$ cycles to constrain the test duration.

\footnotetext{
${ }^{1}$ The abbreviations SG and SL refer to the first and second production batch respectively. Production process and geometry are identical for both batches.
} 
Representative results obtained for specimen SG-04 have been selected to plot hysteresis loops in Fig. 8. A general trend of decreasing stiffness and increasing permanent deformation can be clearly observed by the decreasing slope of the ellipses and the shift of the centre point of the ellipse. The onset of failure was accompanied by a more rapid reduction of stiffness and increase in dissipated energy. These observations agree very well with the findings of Boyd in his study on the integrity of hybrid steel-to-composite joints for marine applications [30].

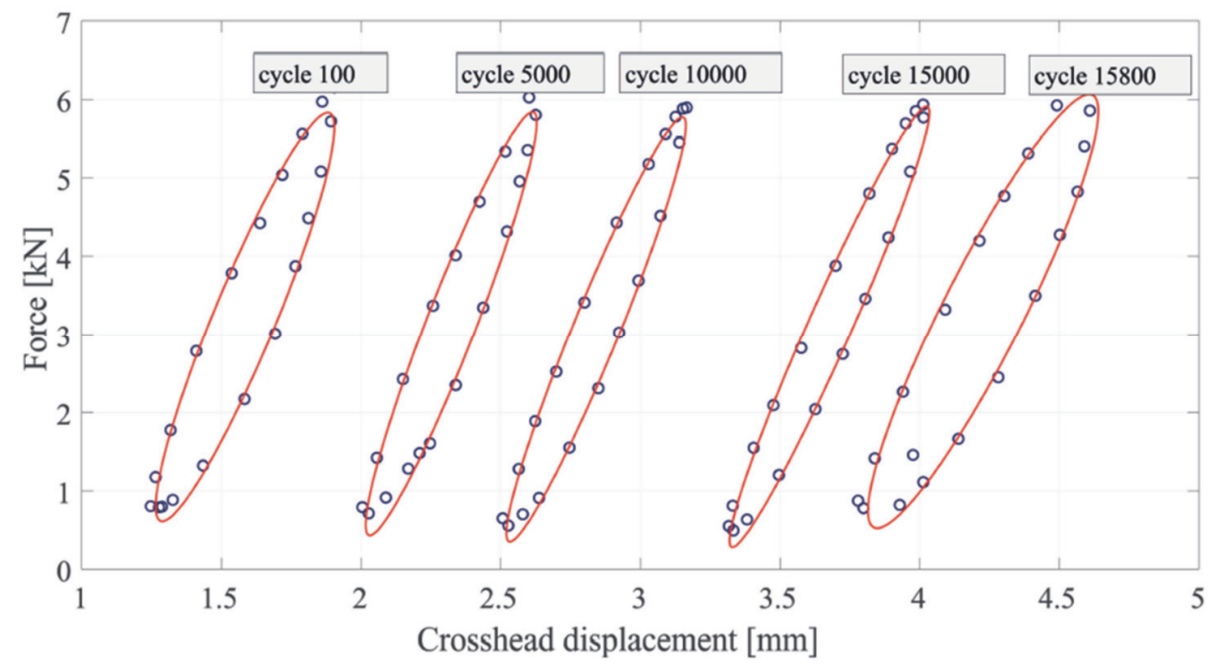

Figure 8: Load-elongation hysteresis loops for SLAJ specimen SG-04.

\section{Double lap adhesive joint specimens}

In total, six DLAJ specimens have been tested at room temperature. First, two quasi-static tensile tests were performed on an MTS servo-hydraulic machine with $1000 \mathrm{kN}$ load cell capacity at a displacement rate of $0.5 \mathrm{~mm} / \mathrm{min}$. The failure loads and corresponding average shear stresses are listed in Tab. 3.

The tensile test results confirmed that a thin adhesive bond line thickness leads to a higher average shear strength (4.9 MPa) as compared to a thick adhesive joint (2.6 MPa) [31-33]. Based on the results of the tensile tests, a maximum fatigue load of $30 \mathrm{kN}$ (corresponding to an average shear stress of $1 \mathrm{MPa}$ ) was defined; the test frequency was set at $4 \mathrm{~Hz}$. The CATF tests were conducted on specimens DL-02 and DL-07 and stopped prior to failure after $5 \times 10^{6}$ and $2.7 \times 10^{6}$ fatigue cycles, respectively, in order to limit the test duration. The ellipses shown in Fig. 9 illustrate the load-displacement data of the double lap joint specimen DL-02 until 1 $1 \times 10^{6}$ cycles.

\begin{tabular}{ccccc}
\hline Sample ID & $\begin{array}{c}\text { Bond line } \\
\text { thickness }(\mathrm{mm})\end{array}$ & $\begin{array}{c}\text { Ultimate load } \\
(\mathrm{kN})\end{array}$ & $\begin{array}{c}\text { Shear Test } \\
(\mathrm{MPa})\end{array}$ & $\begin{array}{c}\text { Sample } \\
\text { after test }\end{array}$ \\
DL-09 & 4 & 147 & 2.6 & Fail \\
DL-05 & 8 & 78 & 4.9 & Fail \\
\hline
\end{tabular}

Table 3: Overview of tensile tests performed on DLAJ specimens.

\begin{tabular}{|c|c|c|c|c|c|c|c|}
\hline Sample ID & $\begin{array}{c}\text { Bond line } \\
\text { thickness(mm) }\end{array}$ & $\begin{array}{l}\text { Type of } \\
\text { Test }\end{array}$ & $\begin{array}{l}\text { Ultimate/range } \\
\text { of load (min - } \\
\max ) \mathrm{kN}\end{array}$ & $\begin{array}{l}\text { Fatigue life } \\
\text { (cycles) }\end{array}$ & $\begin{array}{l}\text { Frequency } \\
(\mathrm{Hz})\end{array}$ & $\begin{array}{c}\text { Load Ratio } \\
(\mathrm{R}=\text { Fmin/Fmax })\end{array}$ & $\begin{array}{l}\text { Sample } \\
\text { after test }\end{array}$ \\
\hline DL-02 & 8 & $\mathrm{CAF}$ & 3-30 & $2.7 \times 10^{6}$ & 4 & 0.1 & Intact \\
\hline DL-07 & 4 & CAF & $3-30$ & $5.0 \times 10^{6}$ & 4 & 0.1 & Intact \\
\hline DL-04 & 8 & VAF & $\begin{array}{c}\text { Stepped loading } \\
\text { of } 7.5\end{array}$ & $6.62 \times 10^{5}$ & 4 & 0.1 & Fail \\
\hline DL-10 & 4 & VAF & $\begin{array}{l}\text { Stepped loading } \\
\text { of } 7.5\end{array}$ & $8.23 \times 10^{5}$ & 4 & 0.1 & Fail \\
\hline
\end{tabular}

Table 4: Overview of fatigue tests performed on DLAJ specimens. 
The dissipated energy per fatigue cycle remained almost constant throughout the test, indicating that this parameter is probably not very sensitive to slightly increased damage. Fig. 10 shows the evolution of the stiffness for DLAJ specimen DL-02; the reported values have been normalized by the initial value of stiffness. The graph shows a noticeable decrease of stiffness at the start, followed by steady progress for the first million cycles. This observation indicates that after the initial 50000 cycles, almost no additional damage is introduced in the specimen.

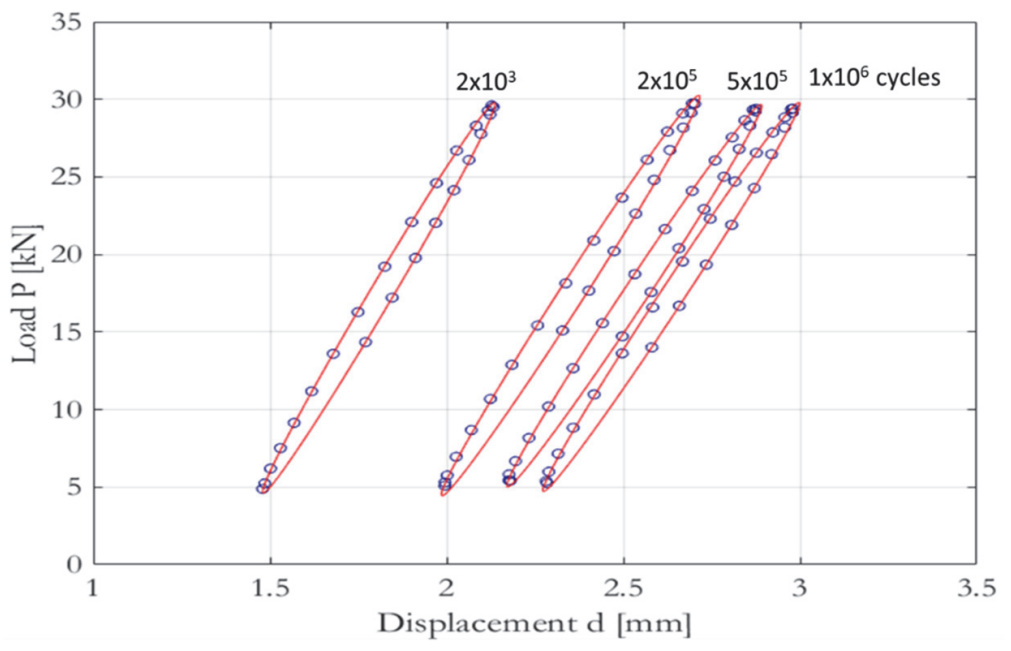

Figure 9: Load-elongation hysteresis loops for DLAJ specimen DL-02.

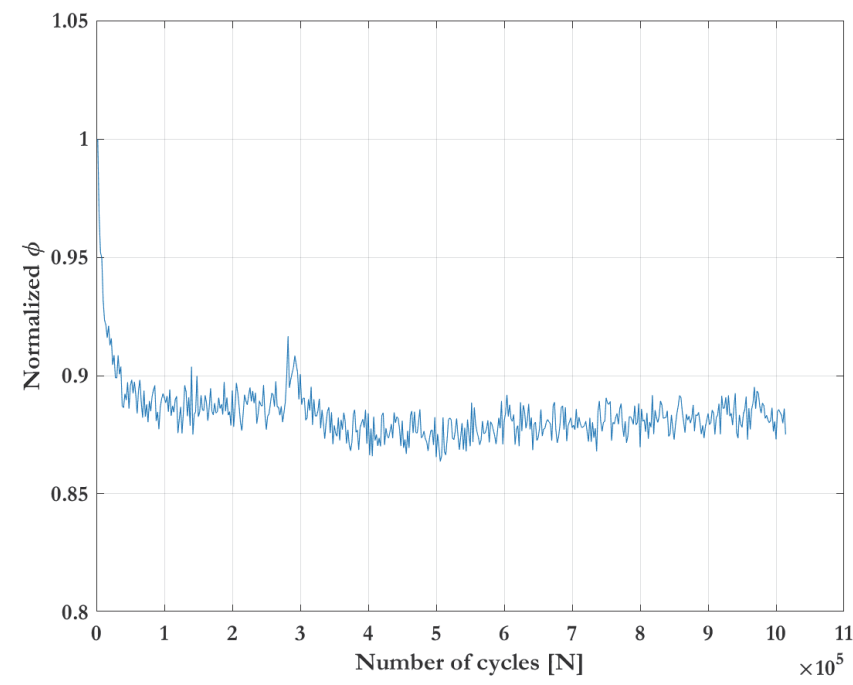

Figure 10: Evolution of damage parameter $\emptyset$ for DLAJ specimen DL-02.

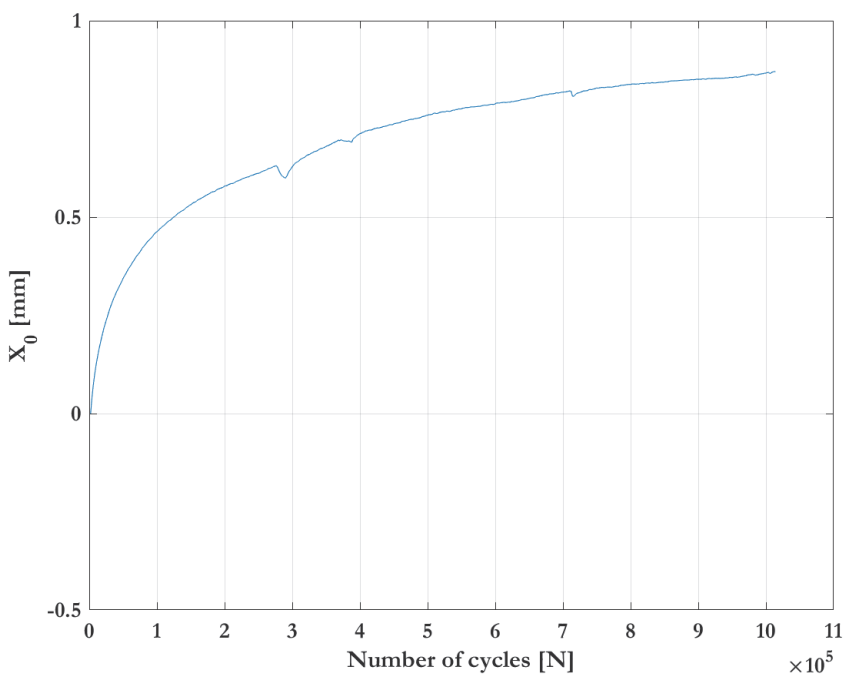

Figure 11: Evolution of centre of ellipse Xo for DLAJ specimen DL-02.

This corresponds with visual observations during the test. Fig. 11 shows the displacement of the centre of the ellipse until 1 million cycles. A significant increase is observed with the increasing number of fatigue cycles. Notwithstanding that no further damage could be observed, the viscoplastic deformation of the adhesive joint keeps on slowly increasing. The variable amplitude fatigue tests were performed up to failure for specimens DL-10 and DL-04 with a bond line thickness of respectively $4 \mathrm{~mm}$ and $8 \mathrm{~mm}$.

The atmospheric conditions, test frequency and methodology of data acquisition were identical to the constant load fatigue tests. The variable amplitude fatigue tests were force-controlled and characterised by load step changes of $0.25 \mathrm{MPa}$ average shear stress. Starting at a load corresponding to $0.25 \mathrm{MPa}$ average shear stress, the load was increased every 100000 cycles. Specimens DL-04 and DL-10 reached a maximum of 662838 and 823265 cycles, respectively. Similar to the observations of the tensile tests, the thick bond line thickness decreases the fatigue strength of the joint compared to a thin adhesive. Representative hysteresis ellipses were obtained without any loss of data points, as demonstrated in Fig. 12 . Fig. 13 shows 
the evolution of damage in terms of normalized energy dissipation for DLAJ specimen DL-04. The energy dissipation increases throughout the test, with more or less constant values during each block. A continuously decreasing stiffness with the increasing number of cycles was found, in line with the above observations and the observations reported in [24]. Fig. 14 shows the displacement of the centre of the ellipse throughout the test. A significant increase is observed at every load block change, and within each load block, the increase in displacement shows a continuous evolution. Between 200000 and 400000 cycles this increase is slow, from 400000 cycles on the displacement of the ellipses increases faster and at 600000 cycles, the displacement is that big that the specimen separated eventually.

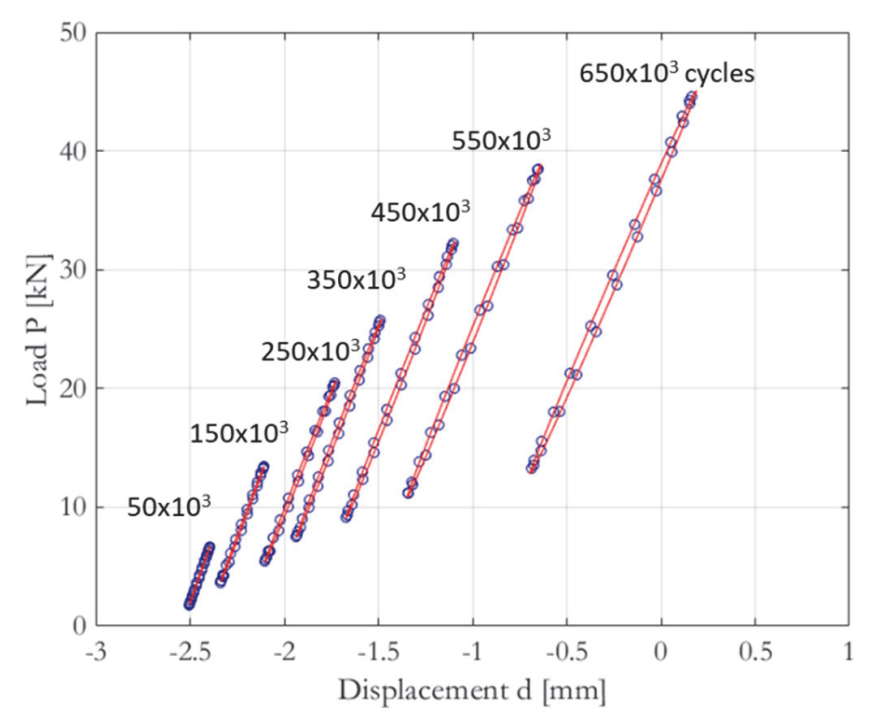

Figure 12: Load-elongation hysteresis loops for DLAJ specimen DL-04.

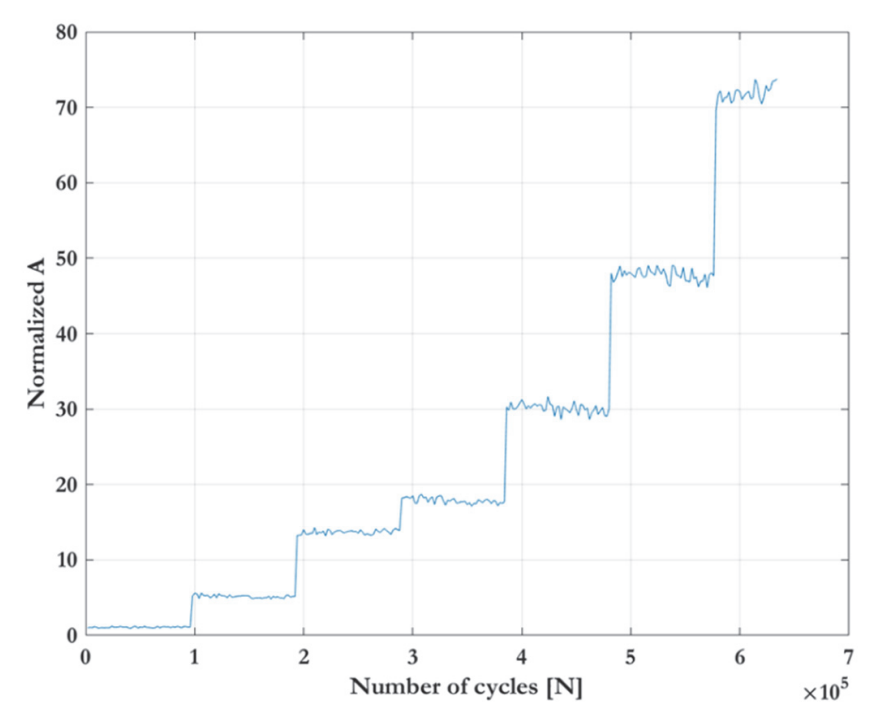

Figure 13: Evolution of damage parameter A for DLAJ specimen DL-04.

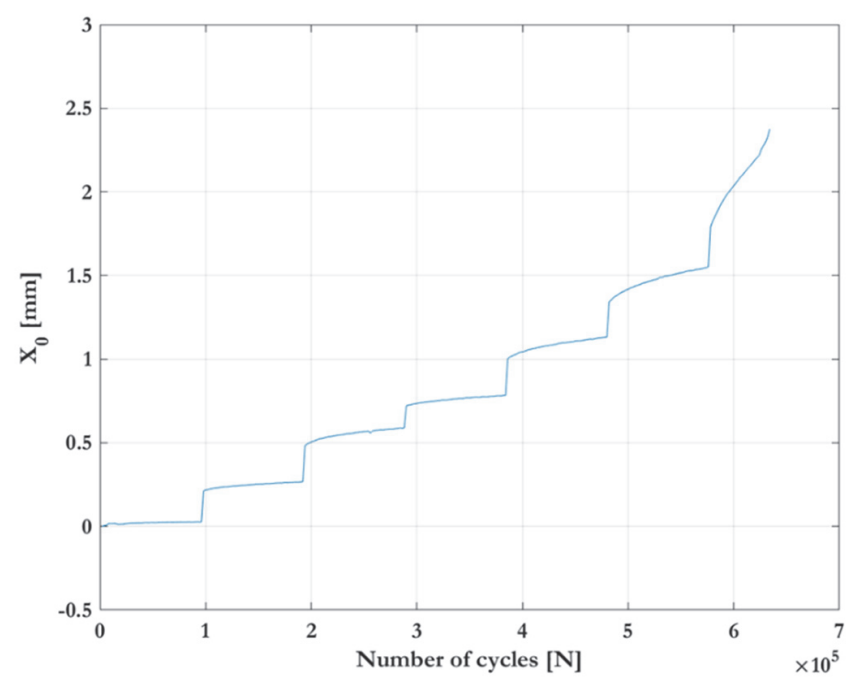

Figure 14: Evolution of change in centre of ellipse Xo for DLAJ specimen DL-04.

\section{CONCLUSION}

$\mathrm{S}$

ingle lap adhesive joint specimens and double lap adhesive joint specimens with two different bond line thicknesses were subjected to a series of constant and variable amplitude fatigue tests. Due to the viscoelastic nature of the MMA adhesive, the load versus elongation curves recorded during fatigue testing show typical hysteretic behaviour. Using DIC for monitoring these tests proved to be a valuable tool for an accurate elongation measurement of the flexible SLAJ 
specimens. To evaluate the fatigue damage, a Matlab code was developed that allows to study the evolution of three characteristics of the hysteresis curves; i.e. the canter of the ellipse (representative of permanent viscoplastic deformation), the slope of the ellipse major axis (representative of the stiffness of the joint) and the enclosed area (representative of the dissipated energy per cycle. A general trend of increasing permanent elongation, decreasing slope and increasing enclosed surface area of the hysteresis ellipses was observed. The results from tests on DLAJ specimens indicated that a larger adhesive thickness was inferior to a smaller thickness in terms of static and fatigue strength.

\section{ACKNOWLEDGEMENT}

7 he authors would like to thanks Thomas Geldhof, Lauren Buyck and Mika Besard for performing the fatigue tests in the framework of their master dissertations. Also thanks to Damen Schelde Naval Shipbuilding (the Netherlands) for manufacturing the double lap joint specimens.

\section{FUNDING}

his research was carried out within the project "QUALIFY-Enabling Qualification of Hybrid Joints for Lightweight and Safe Maritime Transport", co-funded by the INTERREG 2SeasMers Zeeën programme and the province of East-Flanders.

\section{REFERENCES}

[1] Das, S. (2011). Life cycle assessment of carbon fiber-reinforced polymer composites, Int. J. Life Cycle Assess., 16(3), pp. 268-282.

[2] Cheah, L. (2010). Cars on a diet: The material and energy impacts of passenger vehicle weight reduction in the U.S. Doctor of Philosophy in Engineering Thesis, Engineering Systems Division, , pp. 121.

[3] Farrahi, G.H., Kashyzadeh, K.R., Minaei, M., Sharifpour, A., Riazi, S. (2020). Analysis of Resistance Spot Welding Process Parameters Effect on the Weld Quality of Three-steel Sheets Used in Automotive Industry: Experimental and Finite Element Simulation, Int. J. Eng., 33(1), pp. 148-157, DOI: 10.5829/ije.2020.33.01a.17.

[4] Noury, P., Hayman, B., McGeorge, D., Weitzenbock, J. (2002). Lightweight construction for advanced shipbuildingrecent development, Det Nor. Verit. Norw.

[5] Jahnke, J., Molter, L., Mus, R.L. (2019). Adhesive free GFRP-Steel connection for maritime applications. Trends in the Analysis and Design of Marine Structures: Proceedings of the 7th International Conference on Marine Structures (MARSTRUCT 2019, Dubrovnik, Croatia, 6-8 May 2019), CRC Press, p. 353.

[6] Heshmati, M., Haghani, R., Al-Emrani, M. (2015). Environmental durability of adhesively bonded FRP/steel joints in civil engineering applications: State of the art, Compos. Part B Eng., 81, pp. 259-275, DOI: 10.1016/j.compositesb.2015.07.014.

[7] Heshmati, M., Haghani, R., Al-Emrani, M. (2016). Effects of moisture on the long-term performance of adhesively bonded FRP/steel joints used in bridges, Compos. Part B Eng., 92, pp. 447-62.

[8] Colombi, P., Fava, G. (2012). Fatigue behaviour of tensile steel/CFRP joints, Compos. Struct., 94(8), pp. 2407-2417, DOI: 10.1016/j.compstruct.2012.03.001.

[9] Zamani, P., Jaamialahmadi, A., da Silva, L.F.M., Farhangdoost, K. (2019). An investigation on fatigue life evaluation and crack initiation of Al-GFRP bonded lap joints under four-point bending, Compos. Struct., pp. 111433.

[10] Mariam, M., Afendi, M., Majid, M.S.A., Ridzuan, M.J.M., Sultan, M.T.H., Jawaid, M., Gibson, A.G. (2019). Hydrothermal ageing effect on the mechanical behaviour and fatigue response of aluminium alloy/glass/epoxy hybrid composite single lap joints, Compos. Struct., 219, pp. 69-82.

[11] Machado, J.J.M., Marques, E.A.S., Barbosa, A.Q., da Silva, L.F.M. (2019). Fatigue performance of single lap joints with CFRP and aluminium substrates prior and after hygrothermal aging, Fatigue Fract. Eng. Mater. Struct., 42(10), pp. 2325-39, DOI: 10.1111/ffe.13067.

[12] Ayatollahi, M.R., Samari, M., Razavi, S.M.J., da Silva, L.F.M. (2017). Fatigue performance of adhesively bonded single lap joints with non-flat sinusoid interfaces, Fatigue Fract. Eng. Mater. Struct., 40(9), pp. 1355-1363, 
DOI: $10.1111 /$ ffe. 12575 .

[13] Razavi, S.M.J., Ayatollahi, M.R., Samari, M., da Silva, L.F.M. (2019). Effect of interface non-flatness on the fatigue behavior of adhesively bonded single lap joints, Proc. Inst. Mech. Eng. Part L J. Mater. Des. Appl., 233(7), pp. 12771286, DOI: $10.1177 / 1464420717739551$.

[14] Kałuża, M., Hulimka, J. (2017). Methacrylate adhesives to create CFRP laminate-steel joints-preliminary static and fatigue tests, Procedia Eng., 172, pp. 489-96.

[15] Van Lancker, B., Hertelé, S., De Corte, W., Dispersyn, J., De Waele, W., Belis, J. (2016).Application of digital image correlation in linear structural adhesive glass-metal connection testing. GlassCon Global, FCA Conferences, LLC, pp. 305-313.

[16] Colavito, K., Das, M., Hahs, D., Gorman, J., Madenci, E., Smeltzer, S. (1816).Digital Image Correlation for adhesive strains in Bonded Composite Lap Joints. 49th AIAA/ASME/ASCE/AHS/ASC Structures, Structural Dynamics, and Materials Conference, 16th AIAA/ASME/AHS Adaptive Structures Conference, 10th AIAA Non-Deterministic Approaches Conference, 9th AIAA Gossamer Spacecraft Forum, 4th AIAA Multidisciplinary Des, p. 1844.

[17] Rudawska, A., Danczak, I., Müller, M., Valasek, P. (2016). The effect of sandblasting on surface properties for adhesion, Int. J. Adhes. Adhes., 70, pp. 176-90.

[18] Hulimka, J., Kałuża, M. (2017). Preliminary tests of steel-to-steel adhesive joints, Procedia Eng., 172, pp. 385-392.

[19] D-1002-05, A. (2001).Standard test method for apparent shear strength of single-lap-joint adhesively bonded metal specimens by tension loading (metal-to-metal). American Society for Testing Materials.

[20] Dispersyn, J., Hertelé, S., De Waele, W., Belis, J. (2017). Assessment of hyperelastic material models for the application of adhesive point-fixings between glass and metal, Int. J. Adhes. Adhes., 77, pp. 102-117.

[21] Kumar, R.L.V., Bhat, M.R., Murthy, C.R.L. (2013). Experimental analysis of composite single-lap joints using digital image correlation and comparison with theoretical models, J. Reinf. Plast. Compos., 32(23), pp. 1858-1876.

[22] (N.d.). Resolution and Accuracy. Available at: https://www.correlatedsolutions.com/support/index.php?/Knowledgebase/Article/View/8/1/resolution-andaccuracy.

[23] Rutkiewicz, A., Jakobczak, A. (2017). The Digital Image Correlation System Accuracy Direct Testing Using Strain Gauges, Proc. - 2017 Balt. Geod. Congr. (Geomatics), BGC Geomatics 2017, pp. 369-373, DOI: 10.1109/BGC.Geomatics.2017.71.

[24] Savvilotidou, M., Keller, T., Vassilopoulos, A.P. (2017). Fatigue performance of a cold-curing structural epoxy adhesive subjected to moist environments, Int. J. Fatigue, 103, pp. 405-414.

[25] Dattoma, V., Giancane, S. (2013). Evaluation of energy of fatigue damage into GFRC through digital image correlation and thermography, Compos. Part B Eng., 47, pp. 283-239.

[26] Giancane, S., Panella, F.W., Nobile, R., Dattoma, V. (2010). Fatigue damage evolution of fiber reinforced composites with digital image correlation analysis, Procedia Eng., 2(1), pp. 1307-15.

[27] Casas-Rodriguez, J.P., Ashcroft, I.A., Silberschmidt, V. V. (2007). Damage evolution in adhesive joints subjected to impact fatigue, J. Sound Vib., 308(3-5), pp. 467-478.

[28] Marcadon, V., Nadot, Y., Roy, A., Gacougnolle, J.L. (2006). Fatigue behaviour of T-joints for marine applications, Int. J. Adhes. Adhes., 26(7), pp. 481-489.

[29] Veritas, D.N. (2012). Design, Fabrication, Operation and Qualification of Bonded Repair of Steel Structures, Recommended Practice, DNV-RP-C301.

[30] Boyd, S.W., Blake, J.I.R., Shenoi, R.A., Kapadia, A. (2004). Integrity of hybrid steel-to-composite joints for marine application, Proc. Inst. Mech. Eng. Part M J. Eng. Marit. Environ., 218(4), pp. 235-246.

[31] Kahraman, R., Sunar, M., Yilbas, B. (2008). Influence of adhesive thickness and filler content on the mechanical performance of aluminum single-lap joints bonded with aluminum powder filled epoxy adhesive, J. Mater. Process. Technol., 205(1-3), pp. 183-169.

[32] Arenas, J.M., Narbón, J.J., Alía, C. (2010). Optimum adhesive thickness in structural adhesives joints using statistical techniques based on Weibull distribution, Int. J. Adhes. Adhes., 30(3), pp. 160-165.

[33] Ojalvo, I.U., Eidinoff, H.L. (1978). Bond thickness effects upon stresses in single-lap adhesive joints, AIAA J., 16(3), pp. 204-211. 